Ministry of Education Iraqi Directorate of Education Baghdad Karkh III

First Conference Department of Preparation and Training Division of Research and Studies وزارة التربية العراقية مديرية تربية بغداد الكرخ الثالثة المؤتمر الاول قسم الاعداد والتدريب شعبة البحوث والدراسات

\title{
The Impact of The Strategy Analog Thinking in acquiring Social Content Material Concepts of Fourth Primary Class Pupils
}

\author{
Manal Taha Yaseen Al-Ta'ie \\ Directorate of Baghdad Education Karkh III, Ministry of Education, Baghdad, Iraq \\ manalmnw@gmail.com
}

\begin{abstract}
The present study aims the experimental design adopted in the present study is the partial control experimental design of a pre-post control group design. The present study has been limited to the fifth primary class pupils included with in the state primary schools in Baghdad during the academic year (2017-2018), The sample consists of 63 male and female 4th primary class pupils , distributed into 31 ones as an experimental group from Al-Mutanbi Primary school and 32 students as a control group Equalization. The instrument is constructing test measuring concepts acquisition consisted of (8) concepts which consists of (24) items. Experimental group pupils, who have been exposed to Strategy Analog Thinking, have been superior to those at the control group in social content material acquisition.
\end{abstract}

Keywords: The Strategy Analog Thinking, Material Concepts.

\section{أثر استراتيجية التفكير التناظري في اكتساب مفاهيم مادة الاجتماعيات لدى تلامذة الصف الرابع الابتدائي}

\author{
منال طه ياسين الطائي \\ وزارة التربية، هديرية تربية بغداد الكرخ الثالثة، بغداد، العراق \\ manalmnw@gmail.com
}

المسلتخلص ولتحقيق هدف البحث اعتمدت الباحثة المنهج التجريبي، والتصميم التجريبي ذي الضبط الجزئي وهو تصميم المجموعة الضابطة ذات الاختبار البعدي. استمر البحث الحالي فصلاً دراسياً واقتصر على تلامذة الصف الرابع الابتدائي في المدارس الحكوهية في مدينة بغداد للعام الدراسي (2018-2019)، بلغت عينة البحث (63) تلميذ وتلميذة في مدرلةة المتنبي الابتدائية، وبواقع (31) تلميذ وتلميذة في المجموعة التجريبية و(32) تلميذ وتلميذة في المجموعة الضابطة. اعدت الباحثة اختباراً لقياس اكتساب المفاهيم تألف من (8) مفاهيم توزعت على (24) فقرة. واسفرت النتائج عن تفوق تلامذة الهجموعة التجريبية الذين درسوا باستعمال استراتيجية التفكير التناظري على تلامذة المجموعة الضابطة الذين درسوا بالطريقة التقليدية في اكتساب المفاهيم.

الكلمات الدالة: استراتيجية التفكير التناظري، اكتساب المفاهيم.

Al-Ta'ie, M. (2019). The Impact of The Strategy Analog Thinking in acquiring Social Content Material Concepts of Fourth Primary Class Pupils. Journal Port Science Research, 2(3), 375-396. doi.org/10.36371/port.2018.02.3.3 
مع تطور الثورة المعلوماتية والتزايد المعرفي في العلوم الإنسانية بشكل عام والمواد الاجتماعية بشكل خاص، أصبح إلمام الفرد بجميع تلك المعارف معضلة يعاني منها، لذا اتجهت الهؤسسات التربوية نحو تعليم المفاهيم واكتسابها، كونها تشكل وحدات التعلم الأساسية والتي بدونها تبقى الحقائق متراكمة لا يدرك المتعلم العلاقات فيما بينها وكيفية انتقال أثر التعلم الى مواقف جديدة تمكنه من إدراك العالم الخارجي [1] ولكن نظرة إلى واقعنا التربوي نجد بأن هناك تدني في مستوى اكتساب التلاميذ للمفاهيم بشكل عام, وإن أغلب المعلمين والمعلمات يتبعون الطرائق التقليدية في التدريس, والتي تهدف الى تزويد المتعلمين بالحقائق والمعلومات واسترجاعها, بدرجة تفوق الاهتمام بالمفاهيم الجديدة وربطها بما لديهم من مفاهيم سابقة, حيث يأتي تدريس الهفاهيم بشكل عشوائي وغير مقصود, مما يحول دون استيعابها ودمجها في بنيتهم المعرفية, وقد أكد دراسة [2] وجهة نظر الباحثة والتي قوم من خلالها تدريس الجغرافية في المرحلة الابتدائية وفق معايير الجودة الشاملة. وعلى هذا يأتي البحث للإجابة على السؤال الآتي:

هل لإستراتيجية التفكير التناظري أثر في اكتساب مفاهيم مادة الاجتماعيات لدى تلامذة الصف الرابع الابتدائي؟

\section{اهمية البحث}

يعد العصر الحالي عصر التقدم العلمي والتكنولوجي في مختلف مجالات العلم والمعرفة، وظهور النظريات والاتجاهات الحديثة في مجال التربية وعلم النفس التي تهدف الى تطوير العملية التعليمية وهواكبة المستجدات العلمية، والعمل على إعداد الإنسان إعداداً يتناسب مع هذا التقدم [3]. ولم تعد وظيفة التربية تقتصر على تعريف الأفراد بمقومات بيئتهم الطبيعية والاجتماعية التي ينتمون إليها فحسب، بل أخذت تسعى الى تنمية بيئتهم ومجتمعهم، والتعرف الى حاجاتهم وهشكلاتهم وإيجاد الحلول المدروسة لها بكل الوسائل والطرق [4] وعلى هذا ترجم الاهتمام بطرائق التدريس واستراتيجياتها المتعددة, كونها تمثل الوسيلة التي يسلكها المعلم في ايصال المعارف والمعلومات الى المتعلم بكل سهولة ويسر, بحيث تكفل التفاعل بين المعلم وتلاهذته, وبين التلاميذ والمادة الدراسية وهع بعضهم البعض, وينهم وبين مجتمعهم [5] فهي تشكل عنصراً اساسياً من عناصر الهنهج, فهي تعمل على استثارة دافعية المتعلمين الى التعلم, وتجذب اهتمامهم للمهمات المسندة إليهم, وتبث الحياة في المحتوى التعليمي وتزيد مدى الإفادة منه [6] لذا فإن التحديثً

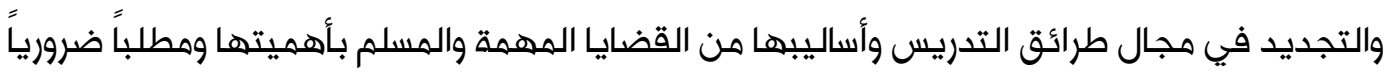
وحيوياً من أجل احداث التوازن بين الحياة السريعة التغيير ودور المؤسسات التعليمية والنظم التربوية ويشير [7] إلى إن الآونة الأخيرة قد شهدت ظهور استراتيجيات وطرائق تدريس حديثة تعتمد على 
نظريات علمية ساهمت في تطوير وتحسين العملية التعليمية مثل النظرية البنائية التي تنظر الى اكتساب المعرفة كعملية نشطة وهستهرة يتم بها تعديل البنية المعرفية للمتعلم بآليات عملية يكون فيها محوراً للعملية التعليمية ويكون المعلم موجهاً ومرشاًً [8]. وتعد استراتيجية التفكير التناظري إحدى هذه الاستراتيجيات التي تنظر الى المتعلم ككائن نشط وفاعل يبني معرفته داخلياً متأثراً بالبيئة التي يعيش فيها واللغة والمجتمع، فهي تنمي الذكاءات المتعددة من خلال السمات والخصائص المشركة بين شيأين وتقريب المفاهيم المجردة وفهمها بشكل أفضل، وهي صفة حهن العلماء في تفكيرهم باستعمال المتناظرات في فهم الظواهر والمفاهيم المركبة [9]. واستراتيجية التفكير التناظري تقوم على خطوات منظمة ومحددة مستندة الى التفكير التناظري الذي يستخدهـ المتعلم لبناء المعرفة وتكوين افتراضات خصبة لفهم الظواهر وتفسيرها والوصول الى حل للمشكلات، من خلال استعمال جزء من معرفته السابقة ومزجها مع الخبرة الجديدة، وللتفكير التناظري دوراً مهما في عملية التصنيف والوصول الى المعرفة وتوضيح العلاقة بين مجموعة من الأشياء [10]. وإن التركيز على المفاهيم العامة والأكثر شهولاً يسهم اسهاماً كبيراً في نهو التلميذ العقلي والمعرفي, إذا تدرجت في الصعوبة والتعقيد وبها يتناسب وهرحلة نمو التلميذ, بدلاً من التركيز على الحقائق الهنفصلة [11].حيث يعد تعلم المفاهيم عامة, ومفاهيم المواد الاجتماعية خاصة, من أهم اهداف التربية في جميع مستويات ومراحل التعليم, فهي ضرورية لتفسير وتعديل المواقف التي يمرون بها, كما أنها تخفف من تعقيدات البيئة, وتسهل على المتعلمين دراسة مكوناتها وظواهرها الهختلفة [12] ويمكن من خلالها تصنيف الأشياء والمواقف ومساعدة الهتعلم على التوجه والتخطيط والتنبؤ وبالتالي التعرف على بيئته وابعادها المختلفة [13]. وقد اختارت الباحثة مرحلة الصف الخامس الابتدائي باعتبارها حجر الأساس في السلم التعليمي والتي تبنى على ضوئها كل مراحل التعليم الاخرى، ولأهميتها في بناء شخصية التلميذ وتنمية قدراته، ومهاراته واتجاهاته، واكسابه العادات والهيول الصحيحة والهقبولة اجتماعياً.

\section{واستناداً لها تقدم تتضح اهمية البحث الحالي بما يأتي:}

(1) يعد البحث الحالي خطوة في طريق التقدم والتطور العلمي من خلال الطرائق والاستراتيجيات

$$
\text { الحديثة بما يسهم في جعل التعلم فاعلاً ومحفزاً داخل الموقف التعليمي الصفي. }
$$

(2) اهمية تعلم المفاهيم كونها تمثل القاعدة الصلبة لباقي مكونات النظام المعرفي من مبادئ ونظريات وتعميمات وتقليل الفجوة بين التعلم السابق واللاحق وبالتالي يكون التعلم ذو معنى.

(3) يمكن أن تسهم هذه الدراسة في تحقيق تعلم أفضل للمفاهيم ضمن مادة الاجتماعيات بوصفها

مقرر دراسي مهم يعنى بدراسة الانسان وأنشطته وتعامله الفعال مع بيئته الطبيعية والبشرية.

Al-Ta'ie, M. (2019). The Impact of The Strategy Analog Thinking in acquiring Social Content Material Concepts of Fourth Primary Class Pupils. Journal Port Science Research, 2(3), 375-396. doi.org/10.36371/port.2018.02.3.3 
(4) يمكن أن تفيد نتائج البحث الحالي الجهات ذات العلاقة بالعملية التربوية في مناهج تدريس المواد الاجتماعية وطرائقها.

(5) اهمية المرحلة الابتدائية كونها تمثل البنية الأساس الانطلاقة الاولى التي يرتقي فيها التلاميذ سلم التعليم والبنية الأساس التي ترتكز عليها الهراحل التعليمية اللاحقة.

\section{هدف البحث وفرضيته}

يهدف البحث الحالي الى التعرف على أثر استراتيجية التفكير التناظري في اكتساب مفاهيم مادة الاجتماعيات لدى تلامذة الصف الرابع الابتدائي. ولتحقيق هدف البحث وضعت الباحثة الفرضية

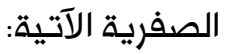

ليس هناك فرق ذو دلالة احصائية عند مستوى (0,05) بين متوسط درجات تلاهذة المجموعة التجريبية الذين يدرسون مادة الاجتماعيات باستراتيجية التفكير التناظري وبين متوسط درجات تلامذة المجموعة الضابطة الذين يدرسون المادة ذاتها بالطريقة التقليدية في اكتساب المفاهيم.

$$
\text { يتحدد البحث الحالي بالآتي: حدود البحث }
$$

(1) تلامذة الصف الرابع الابتدائي في المدارس الحكوهية في محافظة بغداد/ الكرخ 3 للعام الدراسي $.2019-2018$

(2) مفاهيم كتاب الاجتماعيات التي تتضمنها المادة الخاضعة لتجربة البحث المقرر تدريسه للصف الرابع الابتدائي لعام 2018- 2019 والتي تدرس في الفصل الدراسي الأول.

\section{• تصديد المصطلحات الاستراتيجية (Strategy) وعرفها كل من:}

(حميدة وآخرون, 2003): "جميع ما يقوم بع المعلم من إجراءات لتحقيق هدف أو مجموعة اهداف تعليمية محددة لبلوغ النتائج المرجوة". (علي, 2011): "مجموع الأفكار والقرارات التي يتخذها المعلم في أثناء تنفيذ مهامه التعليمية، بغية تحقيق اهداف تم تحديدها سلفاً". [15 التعريف الإجرائي للاستراتيجية: مجموع الإجراءات المنظمة التي تتبعها المعلمة (الباحثة) داخل غرفة الصف أثناء تدريسها المفاهيم الواردة في الوحدة الاولى الخاضعة لتجربة البحث. 
(العفون ومنتهى, 2012) "النشاطات العقلية التي يقوم بها الدماغ عند تعرضه لمثير تم استقباله

$$
\text { بواحدة أو أكثر من الحواس لتحقيق هدف" [17]. }
$$

التعريف الإجرائي للتفكير: هو تمكين تلامذة الصف الرابع الابتدائي على التركيز في محتوى المادة او الموضوع لتوليد أفكار جديدة والربط بين ما هو مألوف وما هو غير مألوف.

التناظر (Analog) عرفه كل من: - (A)

(زيتون, 2002) "أداة معرفية فاعلة تسهل عملية بناء المعرفة للمتعلم على قاعدة من المقاييس التي سبق له تعلمها ودمجها في بنيته المعرفية السابقة".

(قطامي, 2013) "إجراء مقارنة وإيجاد أوجه التشابه والربـط بين مفهوهين أو شيئين وصنع العلاقـات" [18].

التعريف الإجرائي للتناظر: ما تعتمده الباحثة في تدريس تلامذة الهجموعة التجريبية طيلة مدة التجربة ويقوم على ربط فكرة مألوفة مع اخرى غير مألوفة وإدراك التشابه والاختلاف بينهما. الاكتساب (Acquisition) عرفه كل من: (أبو جادو, 2003) "اولى مراحل التعلم التي يتم من خلالها تمثل الفرد للسلوك الجديد ليصبح جزعاً من حصيلته المعرفية" [19].

(سمارة والعديلي, 2008) "ما يكتسبه المتعلم من مهارات أو معلومات بوصفها نتيجة لدراسة موضوع أو مقرر دراسي" [20]. التعريف الإجرائي للاكتساب: قدرة تلامذة الصف الرابع الابتدائي من عينة البحث على إعطاء تعريف للمفاهيم الواردة وتمييز الأمثلة الإيجابية والسلبية من بين ما يعرض عليهم وصولاً الى تعميم ما تم استخلاصه على مواقف اخرى جديدة.

(الشربيني ويسرية, 2000) "تصور عقلي يتم التوصل إليها عن طريق تعميم يستخلص من الخصائص" [21]]. 
j. port. sci. res.
isSN: $2616-7441$

(عبد العزيز; 2009) "مجموعة من السهات أو المظاهر التي تشترك مع بعضها بخاصية أو أكثر وترتبط

التعريف الإجرائي للمفهوم: الصورة العقلية التي يكونها تلاهذة الصف الرابع الابتدائي لكل المفردات ذات الخصائص المشتركة التي يضمها كتاب الاجتماعيات.

المواد الاجتماعية (Social Materials) عرفها كل من:

(الامين, 1990) "وهي المواد التي تهتم بدراسة الأنسان وما يواجه من مشكلات، حيث تضم الجغرافية والتاريخ والتربية الوطنية والاقتصاد" [23].

(قطاوي, 2007) "ذلك الجزء من المحتوى الدراسي المرتبط في علاقته وتعامله الفعال مع البيئة الطبيعية والبشرية، لتحقيق الأهداف التربوية التي تجعل من المتعلمين أفراد نافعين ومواطنين صالحين لمجتمعهم" [24]. الخامس الابتدائي "وهو السنة الرابعة من المرحلة الابتدائية المكونة من ستة صفوف بدءا من الصف الأول حتى الصف السادس، وتشمل الدراسة فيها مواد إنسانية وهواد علمية" [25].

\section{الإطار النظري والدراسات السابقة}

استراتيجية التفكير التناظري Strategy of Analogy Thinking وهي إحدى الاستراتيجيات والنماذج المنبثقة من النظرية البنائية والتي تؤكد على الدور النشط للمتعلم من خلال التفاعل بين ما يمتلكه من معرفة سابقة وبين الخبرات الجديدة، وصولاً لحل ما يواجه من مشكلات، والتي ترتكز على نظرية أوزبل في التعلم ذو المعنى التي تؤكد على أهمية العرض الموجه والمنظم في العملية التعليمية، وكذلك بين الترابط الدقيق بين خبرات المتعلم من ناحية والمادة الجديدة من ناحية اخرى وهو ما

$$
\text { يجعل منها مادة ذات معنى. }
$$

التفكير التناظري أحد أنماط التفكير المستخدم لفهم كل الظواهر الغامضة والهجردة من خلال المعلومات السابقة للمساعدة في حل مشكلة في مجال آخر، وهناك أنواع من التفكير التناظري منها:

$$
\begin{aligned}
& \text { 1) التناظر الواقعي: وهي التناظرات التي تكون قريبة من واقع حياة المتعلم. } \\
& \text { 2) التناظر المصور: وهي التناظرات التي تتم من خلال استعمال الصور والاشكال. } \\
& \text { 3) التناظر في المظهر الخارجي: وهي التناظر الذي يكون باللون أو الحجم أو الشكل. } \\
& \text { 4) التناظر في التركيب أو البناء: وهو التناظر الذي يختص في البناء الداخلي للأشياء. }
\end{aligned}
$$

5) التناظر المركب: وهو استخدام تناظر مألوف لدى المتعلم لتفسير مفاهيم وظواهر غير مألوفة. 
6) التناظر الإجرائي: وهي التناظرات التي يؤديها المعلم من خلال خطوات إجرائية لاكتشاف

$$
\text { ويشر (قطامي, 1998) إلى نوعين من التفكير التناظري هما: }
$$

- التفكير التناظري الهباشر: يقارن الهتعلم فيه بين مفهوهين أو شيئين قريبين كانا أو بعيدين وكلما كان البعد أكبر كان الإبداع أعلى في التوصل لتحديد أوجه التناظر.

- التفكير التناظري الخيالي: يقوم المتعلم بالخروج عن كل ما هو مألوف وتقليدي من خلال إعطاء الفرصة لمخيلته بشكل واسع [26].

\section{دور المتعلم وفق استراتيجية التفكير التناظري}

1) للمتعلم دور اساسي في ربط خبراته السابقة بالخبرات الجديدة، ويقوم بالمقارنات واستخلاص

النتائج.

2) يمارس التناظر لحل ما يواجه من مشكلات.

3) يشترك مع زملاءه وفق مبدأ التعلم التعاوني والتفكير لأستنباط الفرضيات. 4) يكون تناظرات خاصة به ويميز أوجه التشابه والاختلاف في العلاقات.

المفهوم Concept إن ازدياد المعارف والحقائق العلمية في عصر الثورة المعلوماتية، يزيد الحاجة لتعلم المفاهيم، والتي يمكن من خلالها فهم الحقائق وتفسيرها، وكل أنواع التفكير والتعلم وتنمية المهارات، يتطلب فهم واسع للمفاهيم، التي توسع آفاق المعرفة وتسهل تبادل المعلومات والاتصالات مع الآخرين بشكل واسع.

والمفهوم هو محتوى الفكر وناتج عمليات التفكير، كما يشير بياجيه إلى إن المفاهيم الأساسية تتكون ما بين (7- 8) و(11- 12) سنة، وتصل إلى حالة الاتزان في سن 14 سنة فما فوق.

$$
\text { وإن نمو المفاهيم المكانية وتطورها يمر بثلاث مراحل: }
$$

أولا/ (5- 8) سنة عندما يدرك الطفل جسمه واتجاهاته حينها يعي معنى الاتجاهات. ثانيا/ (8- 11) سنة عند وقوع الأشياء بالنسبة لجسهه وللآخرين يفهم الطفل معنى الاتجاهات.

$$
\text { ثالثا/ (11- 12) سنة يدرك المفاهيم المكانية المجردة. }
$$

العوامل المؤثرة في نمو الهفاهيم لدى الأطفال:

$$
\text { هناك العديد من العوامل المؤثرة في نمو المفاهيم لدى الأطفال وهي: }
$$

Al-Ta'ie, M. (2019). The Impact of The Strategy Analog Thinking in acquiring Social Content Material Concepts of Fourth Primary Class Pupils. Journal Port Science Research, 2(3), 375-396. doi.org/10.36371/port.2018.02.3.3 
1) أعضاء الحس: يمكن أن تؤثر حالة وكفاءة أعضاء الحس في نمو الهفاهيم وتعلهها عند المتعلم

$$
\text { كونها تمثل القنوات التي عن طريقها تمر الخبرات الى الدماغ. }
$$

2) الذكاء: الذكاء دور مهم وفاعل في نمو المفاهيم وإدراكها، حيث إن إدراك الطفل الأكثر ذكاءً يكون

$$
\text { أعلى ممن هو أقل ذكاءً. }
$$

3) فرص التعلم: يسهم التعلم في نمو المفاهيم لدى الأطفال، من خلال توفير فرص التعلم المناسبة

$$
\text { في البيئة التي يعيش فيها والتي تزيد من فرص تعلمه وتنمي وخبراته. }
$$

4) نوع الخبرة: يكتسب الطفل في بداية تعلمه المفاهيم من خلال الخبرات المادية المحسوسة المباشرة ثم تتطور فيما بعد ليتم اكتسابها من خلال الخبرات المجردة الغير مباشرة، كالمجسمات

$$
\text { وغيرها. }
$$

الجنس: يبدأ الأطفال بالتفكير والعمل منذ مراحلهم الأولى وبما يتلاءم مع الجنس الذي ينتمون إليه.

الدراسات السابقة

\section{المحور الأول - دراسات تناولت استراتيجية التفكير التناظري:}

دراسة الهسعودي (2014): اجريت هذه الدراسة في العراق، وهدفت الى معرفة (أثر استعمال استراتيجية التفكير التناظري في تحصيل طلاب الصف الرابع العلمي في مادة اللغة العربية)، تكونت عينة الدراسة من (61) طالب موزعين على مجموعتين تجريبية وضابطة، وقد أعد الباحث اختبارا تحصيلي وبعد معالجة البيانات توصلت النتائج الى: وجود فروق ذات دلالة إحصائية بين طلاب

$$
\text { المجموعتين ولصالح المجموعة التجريبية في الاختبار البعدي. [27] }
$$

دراسة الهاشمي: اجريت هذه الدراسة في العراق، وهدفت إلى معرفة (أثر التدريس بالتخيل الموجه وباستراتيجية التفكير التناظري في تحصيل مادة علم البيئة والتلوث والتفكير التأملي لدى طلبة كلية التربية الأساسية)، تكونت عينة الدراسة من (66) طالب وطالبة ولغرض تحقيق هدف البحث أعد الباحث اختباراً في التحصيل واختباراً للتفكير التأملي (لايزك ولسون) وبعد معالجة البيانات باستخدام الحقيبة الاحصائية spss اسفرت النتائج عن: وجود فروق دالة احصائيا لصالح المجموعة التجريبية في اختبار التحصيل والتفكير التأملي [28].

\section{المحور الثاني - دراسات تناولت اكتساب المفاهيم:}

دراسة عبد الرضا: اجريت هذه الدراسة في العراق, وهدفت إلى معرفة (أثر استعمال الخرائط الصم والنماذج المجسمة في اكتساب تلميذات الصف الخامس الابتدائي للمفاهيم والمهارات الجغرافية),بلغت عينة الدراسة(57) تلميذة منها(29) في المجموعة التجريبية الاولى و(28) في

الطائي، منال طه ياسين. (2019). أثر استراتيجية التفكير التناظري في اكتساب مفاهيم مادة الاجتماعيات لدى تلامذة

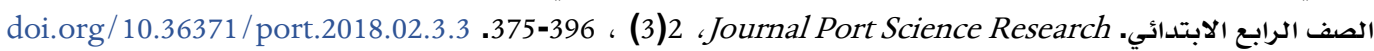


الهجموعة التجريبية الثانية، ولتحقيق هدف البحث اعد اختبارين الاول مؤلف من (30) فقرة لقياس اكتساب المفاهيم الجغرافية, والاخر من (40) فقرة لقياس المهارات الجغرافية وبعد معالجة البيانات اسفرت النتائج : تفوق تلميذات الهجموعة التجريبية الثانية التي تستعمل النماذج المجسمة على تلميذات المجموعة التجريبية الاولى التي تستعمل الخرائط الصم, ولا توجد فروق دالة احصائيا بين المجموعتين في اكتساب المهارات الجغرافية [29]. دراسة الجنديل: اجريت الدراسة في العراق، وهدفت إلى معرفة (أثر استراتيجية تسلق الهضبة في اكتساب المفاهيم الجغرافية لدى طالبات الصف الاول المتوسط)، بلغت عينة الدراسة (85) طالبة ولتحقيق هدف البحث أعدت الباحثة اختبارا لقياس اكتساب المفاهيم تألف من (42) فقرة اختبارية، وقد اسفرت النتائج عن: تفوق طالبات المجموعة التجريبية التي درسن باستراتيجية تسلق الهضبة على المجموعة الضابطة في اختبار اكتساب المفاهيم [30].

منهج البحث وإجراعاته

اولاً منهج البحث: لتحقيق هدف البحث وفرضية اعتمدت الباحثة الهنهج التجريبي وهو ادق الهناهج في البحوث التربوية، ويتم فيه الكشـف عن العلاقـة السببية بين متغيريـن (المستقل والتابع) [31]. التصميم التجريبي: لا بد ان يكون لكل بحث علمي تصميما تجريبياً لكيفية تنفيذ التجربة وتخطيط الظروف والعوامل المحيطة بالظاهرة ولضمان دقة الوصول الى النتائج التي يعول عليها في الإجابة عن الاسئلة التي تطرحها مشكلة البحث وفرضياته [32]. ولتحقيق ذلك اعتمدت الباحثة التصميم التجريبي ذي الضبط الجزئي، وهو تصميم الهجموعة الضابطة ذات الاختبار البعدي والجدول رقم (1) يوضح ذلك:

\section{جدول (1) التصميم التجريبي للبحث}

\begin{tabular}{|c|c|c|c|}
\hline ن الاختبار & المتغير التابع & المتغير المستقل & المجموعة \\
\hline بعدي & اكتساب المفاهيم & استراتيجية التفكير التناظري & التجريبية \\
\hline بعدي & اكتساب المفاهيم & استراتيجية التفكير التناظري & الضابطة \\
\hline
\end{tabular}

\section{مجتمع البحث وعينته}

مجتمع البحث: وقد تمثل مجتمع البحث بتلامذة الصف الرابع الابتدائي في المدارس الابتدائية

عينة البحث: وقد اختارت الباحثة مدرسة المتنبي الابتدائية الهختلطة في قاطع الاسكان لتكون ميداناً لإجراء تجربة البحث وذلك لاحتوائها على أربع شعب للصف الرابع الابتدائي مما يتيح حرية في اختيار

Al-Ta'ie, M. (2019). The Impact of The Strategy Analog Thinking in acquiring Social Content Material Concepts of Fourth Primary Class Pupils. Journal Port Science Research, 2(3), 375-396. doi.org/10.36371/port.2018.02.3.3 
عينة البحث, وعن طريق السحب العشوائي البسيط تم اختيار شعبة (د) لتمثل المجموعة التجريبية التي تدرس مادة الاجتماعيات وفق استراتيجية التفكير التناظري والتي بلغ عدد تلاهذتها (31) تلميذ وتلميذة, وشعبة (ج) لتمثل المجموعة الضابطة التي تدرس المادة ذاتها بالطريقة التقليدية والتي بلغ عدد تلامذتها (33) تلميذ وتلميذة, وتم استبعاد التلامذة الراسبين وعددهم تلميذ واحد في المجموعة الضابطة, وبهذا يكون حجم عينة البحث (63). تكافؤ مجموعتي البحث: كافأت الباحثة بين مجموعتي البحث في عدد من المتغيرات والتي لها أثر على المتغير التابع إلى جانب تأثير المتغير المستقل وهي (العمر الزهني محسوباً بالشهور، اختبار المعرفة السابقة، والتحصيل الدراسي للوالدين، واختبار الذكاء) والجدول (2) يوضح ذلك:

جدول (2) تكافؤ متغير/ت مجموعتي البحث

\begin{tabular}{|c|c|c|c|c|c|c|c|}
\hline \multirow{2}{*}{ الاحصائية } & \multicolumn{2}{|c|}{ القيمة التائية } & \multirow{2}{*}{ الحرجة } & \multirow{2}{*}{ الانحراف } & \multirow{2}{*}{ الحستوسط الحسابي } & \multirow{2}{*}{ المجموعة } & \multirow{2}{*}{ المتغير } \\
\hline & الجدولية & المحسوبة & & & & & \\
\hline \multirow{2}{*}{ غير دالة } & \multirow{2}{*}{1,98} & \multirow{2}{*}{0,10} & \multirow{2}{*}{61} & 2,31 & 111,22 & التجريبية & \multirow{2}{*}{ العمر الزمني } \\
\hline & & & & 2,35 & 111,59 & الضابطة & \\
\hline \multirow{2}{*}{ غير دالة } & \multirow{2}{*}{1,98} & \multirow{2}{*}{0,69} & \multirow{2}{*}{61} & 2,00 & 10,32 & التجريبية & \multirow{2}{*}{ اختبار المعرفة } \\
\hline & & & & 2,19 & 9,96 & الضابطة & \\
\hline \multirow{2}{*}{ غير دالة } & \multirow{2}{*}{1,98} & \multirow{2}{*}{0,71} & \multirow{2}{*}{61} & 6,57 & 21,38 & التجريبية & \multirow{2}{*}{ اختبار الذكاء } \\
\hline & & & & 6,00 & 20,25 & الضابطة & \\
\hline
\end{tabular}

وقد كافأت الباحثة في التحيل الدراسي للوالدين لتلامذة عينة البحث باستعمال معادلة مربع كاي (×²) وبلغت قيمة مربع كاي الهحسوبة للتحصيل الدراسي للآباء (0,34)، وقيمة مربع كاي المحسوبة لتحصيل الأمهات (0,39) وبذلك تكون القيمة المحسوبة لتحصيل الوالدين أصغر من قيمة مربع كاي الجدولية البالغة (7,81) عند مستوى دلالة $(0,05)$ ودرجة حرية (3) مما يدل على تكافؤ مجموعتي البحث.

ضبط المتغيرات الدخيلة: حاولت الباحثة ضبط المتغيرات الدخيلة التي ترتبط بالسلامة الخارجية للبحث (اختيار أفراد العينة، النضج، الاندثار التجريبي، الحوادث الهصاحبة، اداة القياس، أثر الإجراءات التجريبية) والتي قد تؤثر على نتائج البحث على النحو الآتي: (سرية البحث، تدريس المادة، توزيع الحصص الدراسية، الوسائل التعليمية، العشوائية، الظروف الفيزيقية، مدة التجربة).

الطائي، منال طه ياسين. (2019). أثر استراتيجية التفكير التناظري في اكتساب مفاهيم مادة الاجتماعيات لدى تلامذة

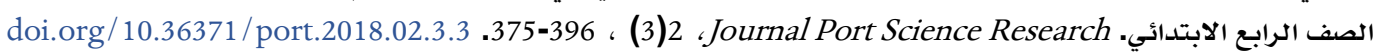


تحديد الهادة التعليمية: حددت الباحثة المادة العلمية الخاضعة للتجربة وهي الفصلين الأولين لهادة الجغرافية، من كتاب الاجتماعيات للصف الرابع الابتدائي للعام الدراسي (2018- 2019) والجدول (2) يوضح ذلك:

جدول (3) محتوى المادة الخاضعة لتجربة البحث وعدد صفحاتها

\begin{tabular}{|c|c|c|}
\hline الصفحة & محتوى الفصل & الفصل \\
\hline $23-5$ & البيئة المحلية & الأول \\
\hline $33-24$ & البيئة الجغرافية & الثاني \\
\hline
\end{tabular}

تحديد مفاهيم مادة الاجتماعيات: لما كان هدف البحث هو قياس اكتساب مفاهيم مادة الاجتماعيات، ولغرض حصرها في المادة الخاضعة لتجربة البحث وهما الفصلين الاولين (الوحدة الأولى) من كتاب الاجتماعيات للصف الرابع الابتدائي، حللت الباحثة محتوى الكتاب المقرر واستخرجت المفاهيم والتي بلغت (8) مفاهيم.

صياغة الاهداف السلوكية: صاغت الباحثة اهدافاً سلوكية في ضوء المفاهيم التي حددت ضمن الفصلين الأولين ضمن الوحدة الأولى وفق عمليات اكتساب المفهوم الثلاث (تعريف، تمييز، تعميم)، وقد بلغ مجموع الأهداف السلوكية (24) هدفاً سلوكياً، على أن يكون لكل مفهوم ثلاث أهداف تمثل عمليات اكتسابه. اداة البحث: من متطلبات البحث الحالي إعداد اختبار لاكتساب المفاهيم التي يتضمنها محتوى كتاب الاجتماعيات للصف الرابع الابتدائي المضهنة في الوحدة والذي يطبق في نهاية الفصل الدراسي الأول عند انتهاء التجربة واتبعت الباحثة في إعداده الخطوات الآتية:

اولا- تحديد الهدف من الاختبار: يسعى الاختبار الحالي إلى قياس اكتساب مفاهيم مادة الاجتماعيات لتلامذة مجموعتي البحث بعد إتمام تدريس الوحدة الأولى. ثانيا- تحديد أبعاد الاختبار: حددت الباحثة أبعاد الاختبار على وفق العمليات الثلاث الخاصة باكتساب المفهوم وهي (تعريف، تمييز، تعميم). ثالثا- صياغة فقرات الاختبار: صاغت الباحثة اختباراً تكون من (24) فقرة اختبارية من نوع الاختيار من متعدد وهو أحد الاختبارات الموضوعية وعلى هذا أصبح للتعريف (8) فقرة اختبارية، ومثلها (8) فقرة اختبارية تقيس التمييز، وللتعميم (8) فقرة اختبارية ايضاً، ولكل فقرة ثلاث بدائل، واحدة صحيحة واثنتان خاطئة مراعية المرحلة العمرية لتلاهذة عينة البحث وملائمتها لطبيعة مادة الاجتماعيات.

Al-Ta'ie, M. (2019). The Impact of The Strategy Analog Thinking in acquiring Social Content Material Concepts of Fourth Primary Class Pupils. Journal Port Science Research, 2(3), 375-396. doi.org/10.36371/port.2018.02.3.3 
1) تعليمات الإجابة: وقد صاغت الباحثة تعليمات الإجابة عن اختبار اكتساب الهفاهيم وكيفية الإجابة عنها بدقة، وتضمنت التعليمات معلومات خاصة بالتلميذ مثل الاسم والصف والشعبة والمدرسة، مع إعطاء مثال توضيحي يرشدهم إلى كيفية الإجابة وعدم ترك أي فقرة دون إجابة، وعدم اختيار أكثر من إجابة للفقرة الواحدة، وزهن الاختبار والدرجة الكلية له.

2) تعليمات التصحيح: اعتمدت الباحثة على إجابة نموذجية في تصحيح فقرات الاختبار (محك تصحيح) إذ اعطيت درجة واحدة للفقرة التي تكون إجابتها صحيحة، وصفر للإجابة الخاطئة أو إو

$$
\text { المتروكة أو التي تتعدد الإجابة عنها. }
$$

خامسا- صدق الاختبار: من أجل التحقق من صدق الاختبار اعتمدت الباحثة نوعين من الصدق هما: الصدق الظاهري وتحقق من خلال عرض فقرات الاختبار مع عمليات اكتساب المفهوم على مجموعة من المحكمين لمعرفة مدى تمثيلها للصفة المراد قياسها، وصلاحيتها. صدق المحتوى وتحقق من خلال تحليل المادة الدراسية تحليلاً دقيقاً وشاملاً لتحديد المفاهيم الخاصة بكل فصل وهوضوع والبالغة (8) مفاهيم وتم تغطيتها بـ (24) هدفاً. سادساً تطبيق الاختبار على العينة الاستطلاعية: للتعرف على مدى وضوح تعليمات اختبار اكتساب المفاهيم وفقراته، والوقت اللازم للإجابة، طبقت الباحثة الاختبار على عينة من تلاميذ الصف الرابع الابتدائي في مدرسة جعفر الطيار الابتدائية المختلطة، والبالغ عددهم (32) تلميذ وتلميذة، واتضح أن الفقرات كانت واضحة وغير غامضة ولم يواجه التلاميذ صعوبة في الإجابة عليها، وتم حساب الوقت المستغرق وتقسيهه على عددهم الكلي وكان (45) دقيقة.

سابعاً التحليل الإحصائي لفقرات الاختبار: اختارت الباحثة عينة التحليل الاحصائي البالغة (100) تلميذ وتلميذة وتم تصحيح الاجابات وترتبها تنازليا من اعلى درجة الى اقل درجة، ومن ثم اختيرت العينتين الهتطرفتين العليا والدنيا (27٪) من عينة التحليل الاحصائي، بهذا أصبح عدد التلامذة في دي دئ كل مجموعة (27) تلميذ وتلميذة من مجموع العينة الكلية لاستخراج: معامل صعوبة الفقرات: وعند حساب معامل صعوبة كل فقرة من فقرات الاختبار وجدتها تتراوح بين (0,71-0,32) وبذلك تعد مقبولة إذا تراوحت درجة صعوبتها (0,20-0,80) وهذا ما أشار إليه (بلوم, 
قوة تمييز الفقرات: وعند حساب القوة التمييزية لكل فقرة من فقرات الاختبار نجدها تتراوح بين (0,67-0,31) وبذلك تعد جميع الفقرات مقبولة، كما أشار (بلوم, 1972) إلى أن الفقرات تعد صالحة إذا كان معامل تمييزها 30 فأعلى.

ثامناً ثبات الاختبار: اعتمدت الباحثة معادلة (كودر ريتشاردسون 20) وذلك لكون الاختبار ثنائي التصحيح (صفر,1) وقد بلغ معامل الثبات (83\%) وهو معامل ثبات جيد. تاسعاً- الوسائل الإحصائية: استعملت الباحثة الوسائل الإحصائية الآتية في معالجة البيانات: الاختبار التائي (T- test) لعينتين مستقلتين، مربع كاي (x²) معادلة صعوبة/ سهولة، معادلة تمييز الفقرات، فعالية البدائل الخاطئة، معادلة (كودر- ريتشاردسون 20).

\section{3. عرض النتائج وتفسبيرها}

عرض النتيجة: للتحقق من الفرضية الصفرية التي نصت على أنه (ليس هناك فرق ذو دلالة احصائية عند مستوى (0,05) بين متوسط درجات تلاهذة المجموعة التجريبية الذين يدرسون مادة الاجتماعيات باستراتيجية التفكير التناظري وبين متوسط درجات تلامذة المجموعة الضابطة الذين يدرسون المادة ذاتها بالطريقة التقليدية في اكتساب المفاهيم). وبعد تطبيق اختبار اكتساب المفاهيم تم حساب المتوسط الحسابي والانحراف المعياري والتباين لتلامذة مجموعتي البحث (التجريبية والضابطة) وباستعمال الاختبار التائي (t-test) لعينتين مستقلتين، وكما موضح في جدول (4): جدول (4) المتوسط الحسابي والانحراف المعياري والتباين والقيمة التائية المحسوبة والجدولية لدرجات/ختبار اكتساب المفاهيمر لتلامذة مجموعتي البحث

\begin{tabular}{|c|c|c|c|c|c|c|c|c|}
\hline \multirow{2}{*}{ الإحصائية } & \multicolumn{2}{|c|}{ القيمة التائية } & \multirow{2}{*}{ درجة } & \multirow{2}{*}{ التباين } & \multirow{2}{*}{ الانحراف } & \multirow{2}{*}{ الحسط الحسبي } & \multirow{2}{*}{ العينة } & \multirow{2}{*}{ المجموعة } \\
\hline & الجدولية & المحسوبة & & & & & & \\
\hline \multirow{2}{*}{ دالة عند } & \multirow[b]{2}{*}{1,98} & \multirow[b]{2}{*}{5,64} & \multirow[b]{2}{*}{61} & 4,78 & 2,18 & 18,45 & 31 & التجريبية \\
\hline & & & & 4,63 & 2,15 & 15,40 & 32 & الضابطة \\
\hline
\end{tabular}

تفسير النتيجة: يمكن أن يعزو تفوق تلامذة المجموعة التجريبية الذين درسوا مادة الاجتماعيات وفق استراتيجية التفكير التناظري على المجموعة الضابطة الذين درسوا وفق الطريقة التقليدية في اكتساب المفاهيم إلى ما يلي:

1) إن التدريس على وفق استراتيجية التفكير التناظري ساعد على انتقال العملية التعليمية من النهط التعلم التقليدي القائم على الحفظ والاستظهار الى النمط القائم على المشاركة النشطة والفاعلة للموقف التعليمي البحث والتساؤل والمشاركة الفاعلة النشطة واستكشاف المفاهيم، ليتسنى

Al-Ta'ie, M. (2019). The Impact of The Strategy Analog Thinking in acquiring Social Content Material Concepts of Fourth Primary Class Pupils. Journal Port Science Research, 2(3), 375-396. doi.org/10.36371/port.2018.02.3.3 
للتلميذ دمجها في بنيته المعرفية حيث يؤكد بياجيه إن المفاهيم تبنى بالفعل والعمل من

$$
\text { قبل المتعلم ولا يمكن استيعابها بالاستماع فقط. }
$$

2) إن التفكير التناظر عمل على إثارة انتباه التلاميذ وتقريب صورة المفاهيم المجردة واكتشاف ما

$$
\text { بينها من علاقات. }
$$

3) إن التعليم وفق التناظرات ساعد في تحديد المشكلة وفهمها ثم محاولة حلها من خلال عد من المهارات التي تركز على التصور والخيال والمماثلة والتشبيه والمجاز، مما انعكس على مستوى

$$
\text { التلاميذ العلمي ورفع تحصيلهم الدراسي. }
$$

4) راعت الفروق الفردية بين التلاميذ وأثارت دافعيتهم عند تقديم موضوع التناظر، فشغفهم ذلك للوقوف على ما يجمع بين موقفين لا تماثل حقيقي بينهما، كان حافزاً لهم لتعلم المفاهيم

$$
\text { الجديدة وجعلها مألوفة لديهم. }
$$

5) أتاحت الفرصة امام التلاميذ للعمل في مجموعات صغيرة تجمعهم اهتمامات مشتركة لأن يفكروا ويتفاعلوا مع ما يسمعوا ويشاهدوا، وبالتالي نقل أثر التعلم الى مواقف جديدة من

$$
\text { حياتهم اليوهية. }
$$

6) إن إعطاء الأمثلة الخاصة بالمفاهيم والتمييز بينها وتطبيقها في بيئة التعلم أو في موقف جديد

$$
\text { يزيد من خبرة التلاميذ ويوسع معلوماتهم. }
$$

الاستنتاجات في ضوء نتيجة البحث، استنتجت الباحثة الآتي:

1) إن التعليم وفق استراتيجية التفكير التناظري قد أثبت فاعليته في اكساب التلاميذ لمفاهيم مادة

$$
\text { الاجتماعيات التي تدرس لأول مرة وتقريبها إلى أذهانهم. }
$$

2) ساهمت استراتيجية التفكير التناظري في الخروج عن كل ماهو تقليدي ومألوف، إذ أصبح تلميذ

$$
\text { المرحلة الابتدائية عنصراً فعالاً في الموقف التعليمي الصفي. }
$$

3) إن استعمال استراتيجية التفكير التناظري قد اتاحت للتلميذ الفرصة في دمج ماتعلم من معارف

$$
\text { ومفاهيم بصورة منتظمة الى بنيته المعرفية. }
$$

4) وفرت استراتيجية التفكير التناظري جو من التفاعل يسمح للتلامذة بالعمل مع زملائهم لاكتشاف

$$
\text { المفاهيم بأنفسهم في جو من الألفة والانسجام. }
$$

$$
\text { التوصيات في ضوء نتيجة البحث، توصي الباحثة بالآتي: }
$$

1) الأخذ بنتائج البحوث والدراسات والتي اثبتت فاعليتها وهنها الدراسة الحالية من أجل رفع المستوى

$$
\text { التعليمي وتحقيق الاهداف التربوية المنشودة. }
$$

الطائي، منال طه ياسين. (2019). أثر استراتيجية التفكير التناظري في اكتساب مفاهيم مادة الاجتماعيات لدى تلامذة

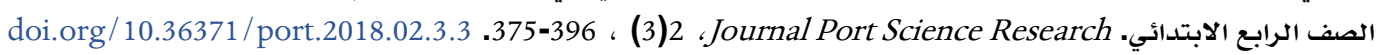


2) فتح الدورات التطويرية من قبل وزارة التربية لمعلميها في أثناء الخدمة، وادخال الطرائق

$$
\text { واستراتيجيات التدريس الحديثة موضع التطبيق. }
$$

3) حث واضعي الهناهج في وزارة التربية والقائمين على تأليف كتاب الاجتماعيات على زيادة

$$
\text { الاهتمام بالمفاهيم وتعزيزها بالتعريفات والأهثلة والتطبيقات. }
$$

4) حث المعلمين والمعلمات أن يوفروا مواقف تعليمية تعطي التلاميذ حرية المشاركة والتعبير عن

$$
\text { آلرقائهم في جو تعليمي اجتماعي ينمي العلاقات الإنسانية المتبادلة. }
$$

1) دراسة تتحرى أثر استراتيجية التفكير التناظري مع متغيرات اخرى كالتحصيل والدافعية والاتجاه،

$$
\text { وهراحل دراسية اخرى. }
$$

2) دراسة تتحرى أثر استراتيجية التفكير التناظري عند تلامذة الصف الرابع الابتدائي وفق متغير

الجنس.

3) مقارنة استراتيجية التفكير التناظري مع استراتيجيات بنائية اخرى وبيان أثرها في اكتساب المفاهيم وتنمية أنواع من التفكير لاسيما التفكير التأملي أو الناقد.

\section{References}

[1] الحيلة, محمد محمود. (2008). اساسيات تصميم وإنتاج الوسائل التعليمية. ط3, دار المسيرة للنشر والتوزيع، عمان، الاردن، ص:

[2] الزبيدي, سعد محمد حمزة. (2012). تقويم تدريس الجغرافية في المرحلة الابتدائية في ضوء معايير الجودة الشاملة. رسالة ماجستير غير منشورة، كلية التربية الأساسية، الجامعة المستنصرية. [3] مازن, حسام محمد. (2015). تدريس العلوم والتربية العلمية من السلوكية الى البنائية. ط1, المكتبة المصرية للنشر والتوزيع، المنصورة، ص:214

[4] خليل, عيادة بياوي. (1996). تدريس العلوم بمدارس المرحلة الثانوية العامة. دار الكتاب المصري، القاهرة، ص : [5] دروزة, أفنان نظير. (2000). النظرية في التدريس وترجمتها عملياً. مطبعة دار الشروق، عمان، الاردن، ص : 
j. port. sci. res.
ISSN: 2616-7441

[6] خضر, فخري رشيد. (2005). اساسيات التدريس الصفي. الدراسات الاجتماعية في المرحلة الابتدائية، دار العلم للنشر

$$
\text { 9: والتوزيع، الامارات، ص }
$$

[7] عباس, محمد ومحمد العبسي. (2007). مناهج واساليب تدريس الرياضيات في المرحلة الأساسية. دار المسيرة للنشر

$$
\text { والتوزيع، عمان، ص : }
$$

[8] (يتون, كمال. (2002). تدريس العلوم للفهم (ؤية بذائية. ط1 , عالم الكتب، القاهرة، ص، ( 198- 252).

[9] أمبو سعيدي, عبد الله بن خميس وسليمان بن تدريس بن البلوشي. (2009). طرائق تدريس العلوم مفاهيم وتطبيقات

$$
\text { عملية. دار المسيرة، عمان، الاردن. }
$$

Diarmuid. O. (2004). Finding Novel Analogies. The thesis is submitted to University College [10] Dublin for the degree of $\mathrm{PhD}$ inthe Faculty of Science.

$$
\text { [11] [11] منصور, علي. (1991). علم النفس التربوي. ط2, مطبعة خالد بن الوليد، دمشق، ص: } 254 \text { اللقاني, احمد حسين. }
$$

[14] حميدة, إمام مختار وآخرون. (2003). تدريس الدراسات الاجتماعية في التعليم العام. ج2, مكتبة زهراء المعادي،

[15] علي, محمد السيد. (2011). اتجاهات وتطبيقات حديثة في الهناهج وطرق التدريس. ط1, دار المسيرة للطباعة والنشر والتوزيع، عمان، الاردن، ص 157

[16] قطامي, نايفة. (2009). تفكير وذكاء الطفل. ط1 , دار المسيرة للنشر والتوزيع، عمان، ص22-13

[17] العفون، نادية حسين ومنتهى مطشر عبد الصاحب. (2012). التفكير أنماطه ونظرياته واساليب تعليمه وتعلمه. ط1, دار صفاء للنشر والتوزيع، عمان، الاردن، ص21

[18] قطامي, يوسف. (2013). استراتيجيات التعلم والتعليم. ط1 , دار المسيرة للنشر والتوزيع، عمان، الاردن، ص725-736

$$
\text { [19] أبو جادو، صالح محمد علي. (2003). علم النفس التربوي. ط3, دار المسيرة للنشر والتوزيع عمان، الاردن، ص } 424
$$

[20] سمارة، نواف احمد وعبد السلام موسى العديلي (2008) : مفاهيم ومصطلحات في العلوم التربوية, ط1 , دار المسيرة

$$
\text { للنشر والتوزيع والطباعق, عمان, ص: } 25
$$

[21] الشربيني، زكريا ويسرية صادق. (2000). نمو المفاهيم العلمية للأطفال برنامج- مقترح وتجارب لطفل ما قبل المدرسة.

$$
\text { دار الفكر العربي، القاهرة، ص93-93 }
$$

[22] عبد العزيز، سعيد. (2009). تعليم التفكير ومهاراته تدريبات وتطبيقات عملية. ط1, دار الثقافة للنشر والتوزيع، عمان، 
[23] الأمين، شاكر محمود. (1990). اصول تدريس المواد الاجتماعية. وزارة التعليم العالي والبحث العلمي، كلية التربية،

[24] قطاوي، محمد إبراهيم. (2007). طرق تدريس الدراسات الاجتماعية. ط1 , دار الفكر ناشرون وموزعون، عمان.

[25] وزارة التربية، جمهورية العراق. (1991). الاهداف التربوية في العراق. مطبعة وزارة التربية، اعداد المديرية العامة للمناهج والوسائل التعليمية، مديرية المناهج والكتب، بغداد، ص77

[26] قطامي، يوسف. (1998). استراتيجيات التعلم والتعليم المعرفية. ط1 , دار المسيرة للنشر والتوزيع، عمان، الاردن،

[27] المسعودي، علي صافي. (2014). أثر استعمال استراتيجية التفكير التناظري في تحصيل طلاب الصف الرابع العلمي في مادة قواعد اللغة العربية. رلسالة ماجستير غير منشورة، كلية التربية الاساسية، جامعة بابل، العراق. [28] الهاشمي، علي ربيع. (2016). أثر التدريس بالتخيل الموجه باستراتيجية التفكير التناظري في تحصيل هادة علم البئة والتلوث والتفكير التأملي لدى طلبة كلية التربية الأساسية. اطروحة دكتوراه غير منشورة، كلية التربية ابن الهيثم،

[29] عبد الرضا، نجدت عبد الرؤوف. (2003). أثر استعمال الخرائط الصم والنماذج المجسمة في اكتساب تلميذات الصف الخامس الابتدائي للمفاهيم والمهارات الجغرافية. اطروحة دكتوراه غير منشورة، كلية التربية أبن رشد، جامعة بغداد. [30] الجنديل، دعاء حسام حسين. (2012). أثر استراتيجية تسلق الهضبة في اكتساب المفاهيم الجغرافية لدى طالبات الصف الأول المتوسط. رسالة ماجستير غير منشورة، كلية التربية الأساسية، الجامعة المستنصرية. [31] عباس، محمد خليل وآخرون. (2011). مدخل الى مناهج البحث في التربية وعلم النفس. ط2 ,دار المسيرة للنشر والتوزيع، عمان، ص79

[32] الزوبعي، عبد الجليل ومحمد احمد الغنام. (1981). مناهج البحث في التربية. مطبعة جامعة بغداد، العراق، ص102 
j. port. sci. res.
isSN: $2616-7441$ Volume:2, No:3

\section{ملحق (1)}

\section{المفاهيم والفقرات الاختبارية التي تقيسها}

\begin{tabular}{|c|c|c|c|}
\hline الفقرة الاختبارية & عمليات اكتساب & المفهوم & ت \\
\hline 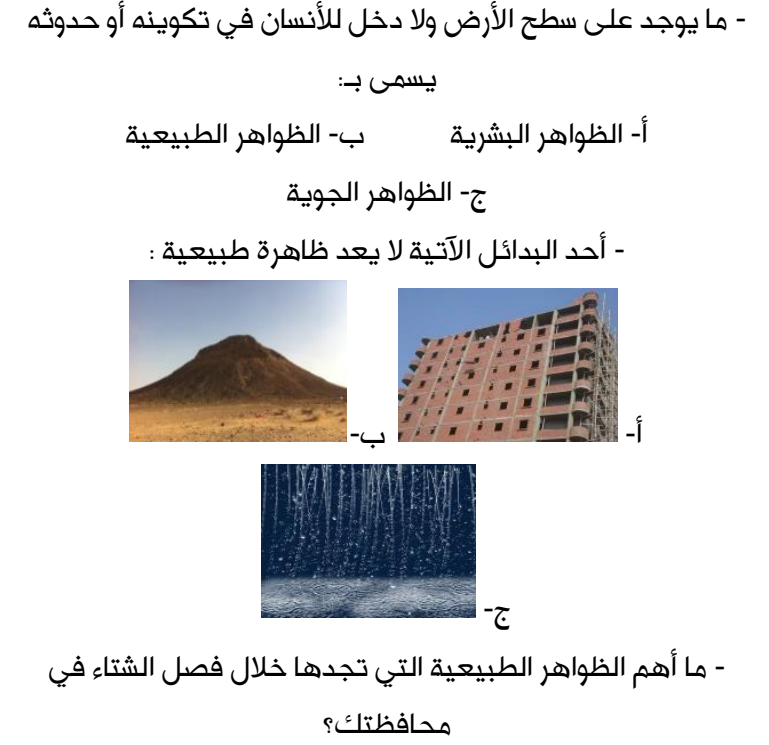 & تعريف تمييز & الظواهر الطبيعية & 1 \\
\hline 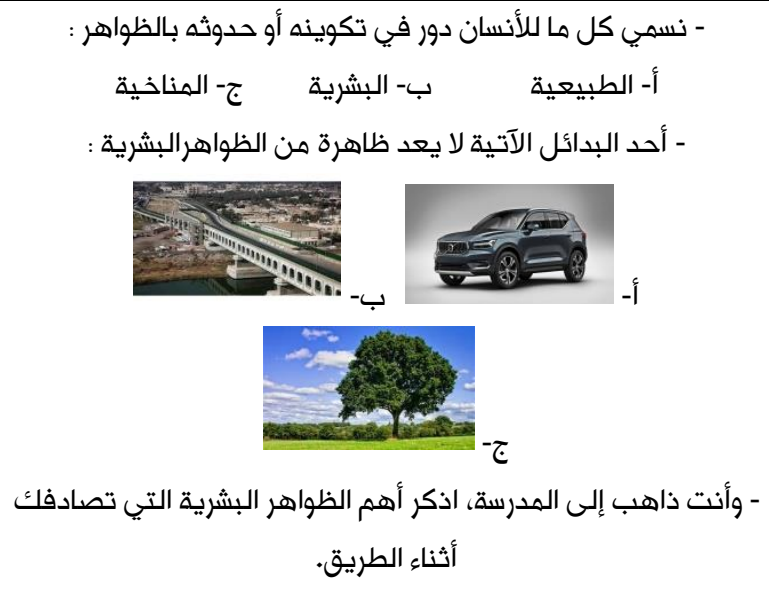 & تعريف تمييز & الظواهر البشرية & 2 \\
\hline 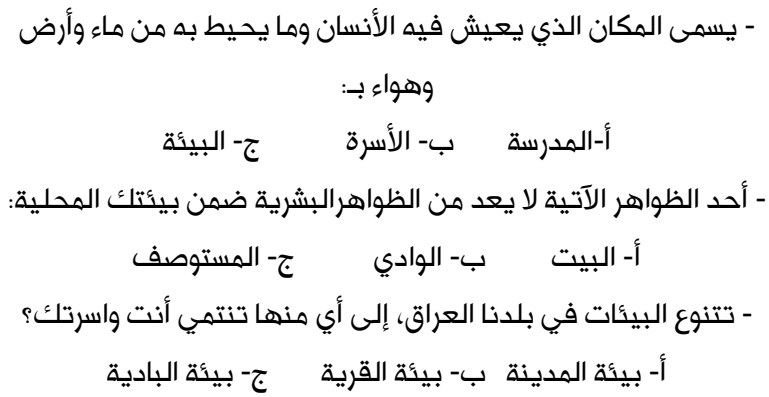 & تعريف تمييز & البيئة & 3 \\
\hline
\end{tabular}

الطائي، منال طه ياسين. (2019). أثر استراتيجية التفكير التناظري في اكتساب مفاهيم مادة الاجتماعيات لدى تلامذة

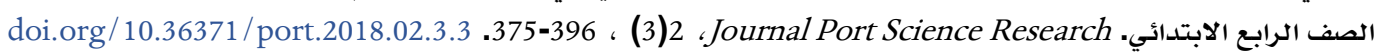


j. port. sci. res
ISSN: 2616-7441

رلسم مصغرأو مخطط مبسط يمثل سطح الكرة الأرضية أو لجزء منها

$$
\begin{aligned}
& \text { يعرف بـ: } \\
& \text { أ- الصورة ب- البوصلة الخريطة }
\end{aligned}
$$

- أحد البدائل الآتية لا ينتمي الى عناصر الخريطة:

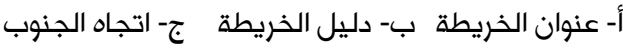

- تعد الخريطة من الأدوات كونها تستعمل في معرفة :

أ- مواقع الموانىء والمدن ب- الظاهر الهناخية

$$
\text { ج- الثروات الطبيعية }
$$

يطلق على النسبة بين المسافة الحقيقية على الأرض والمسافة على

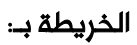

ا- مفتاح الخريطة ب- مقياس الرلام ج- آطار الخريطة

أحد البدائل الآتية يعد من خصائص مقياس الرسم

أ- يوضع أسفل الخريطة ب- يوضع أعلى الخريطة

$$
\text { ج- يحيط بالخريطة }
$$

- نستخدم مقياس الرسم في الخرائط وذلك لـ:

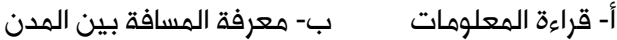

$$
\text { ج- توزيع الظواهر }
$$

- كلمات معينة نستخدمها لتحديد أماكن الظواهر الطبيعية والبشرية

$$
\text { بصورة صحيحة: }
$$

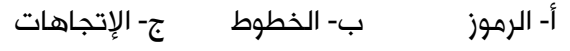

- أحد البدائل الآتية لا تعد من خصائص الإتجاهات ومهميزاتها في

$$
\text { تحديد: }
$$

أ- سرعة دوران الأرض ب- إتجاه القبلة ج- مواقع الدول

- وأنت جالس في الصف وكان اتجاه الشمال يمثل السبورة، تعرف

على باقي الاتجاهات من خلال أجزاء الصف الاخرى.

- تجمع سكاني كبير المساحة, يعرف سكانه بالحضرهو :

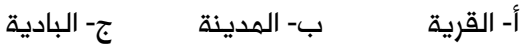

- أحد البدائل الآتية لا يمثل الخصائص التي تتمتع بها المدينة : أ- المباني العالية ب- كثرة السكان ج- قلة الخدمات

- أي المدن تذهب إليها صيفاً لغرض السياحة والأصطياف :

ب- البصرة السماوة

أ- أربيل

تعريف تمييز

مقياس الرسم

5

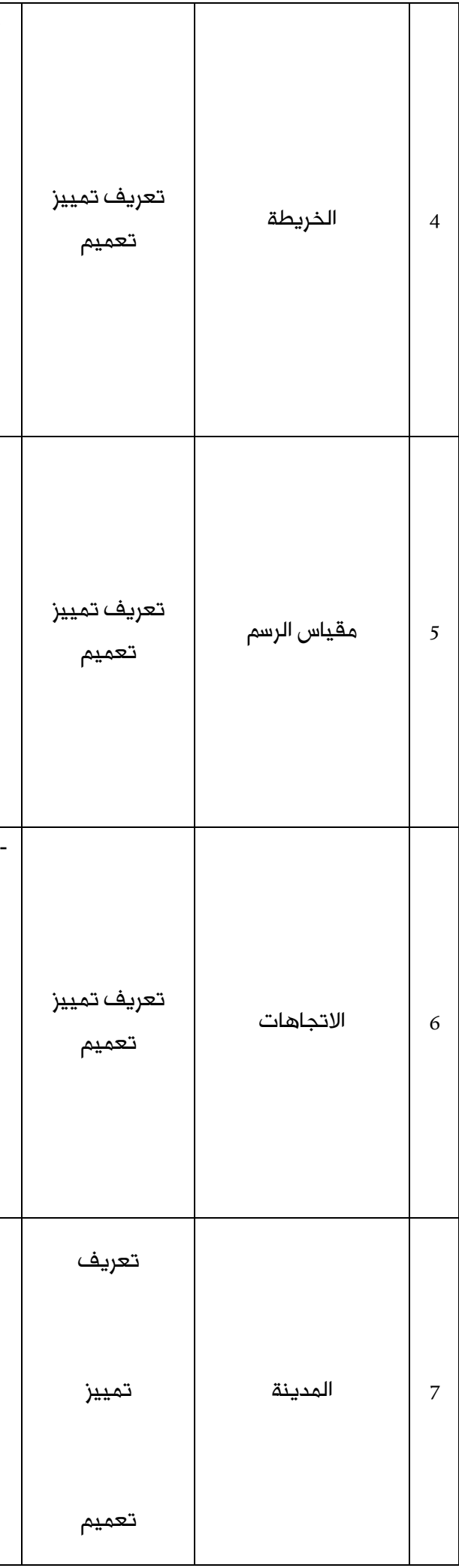

Al-Ta'ie, M. (2019). The Impact of The Strategy Analog Thinking in acquiring Social Content Material Concepts of Fourth Primary Class Pupils. Journal Port Science Research, 2(3), 375-396. doi.org/10.36371/port.2018.02.3.3 
j. port. sci. res.
ISSN: $2616-7441$

(Online)

- تجمع سكاني صغير المساحة قليل السكان، يعرف سكانه بالقرويين

$$
\begin{aligned}
& \text { فأنه يسمى: }
\end{aligned}
$$

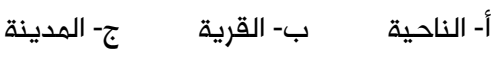

- أحد البدائل الآتية لا يعد من مميزات القرية:

أ- الهواء النقي ب- انخفاض دخل الفرد ج- الضوضاء

- نلاحظ تأثر اغلب مباني البيئة الريفية بالظروف المناخية، والسبب

يعود لمواد البناء والتي اغلبها مصنوع من:

أ- الطين والطابوق ب- الاسمنت ج- الحديد المسلح

\section{الملحق (2)}

أنموذج خطة تدريسية على وفق استراتيجية التفكير التناظري لتلامذة المجموعة التجريبية

$$
\text { الهوضوع / البيعات الجغرافية }
$$

الجانب المهاري:

1) يوظف حاسة السمع والبصر في التعرف على كل ما يميز بيئة المدينة عن غيرها من البيئات.

2) يحاول التأشير على مخطط يبين اسم المشكلة والموقف المسبب لها داخل المدينة.

الوساءل التعليمية:

$$
\text { 1) السبورة والأقلام الملونة لتدوين الملخص السبوري. }
$$

التهيئة: (3دقائق)

نبدأ الدرس بالترحيب بالتلامذة، ثم تهيئة أذهانهم وجذب أنتباههم من خلال مراجعة الدرس السابق، ثم من خلال الألقاء أبدأ بطرح المفهوم المستهدف (بيئة المدينة) بعد توضيح البيئة الجغرافية وأنها تمثل المكان الذي يعيش فيه الانسان،

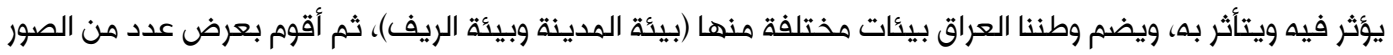
والاشكال التي توضح معالم الهدينة واهم ما يميزها.

الطائي، منال طه ياسين. (2019). أثر استراتيجية التفكير التناظري في اكتساب مفاهيم مادة الاجتماعيات لدى تلامدة

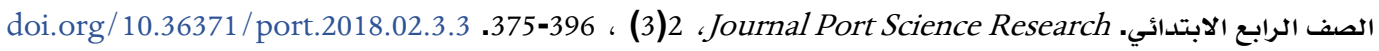



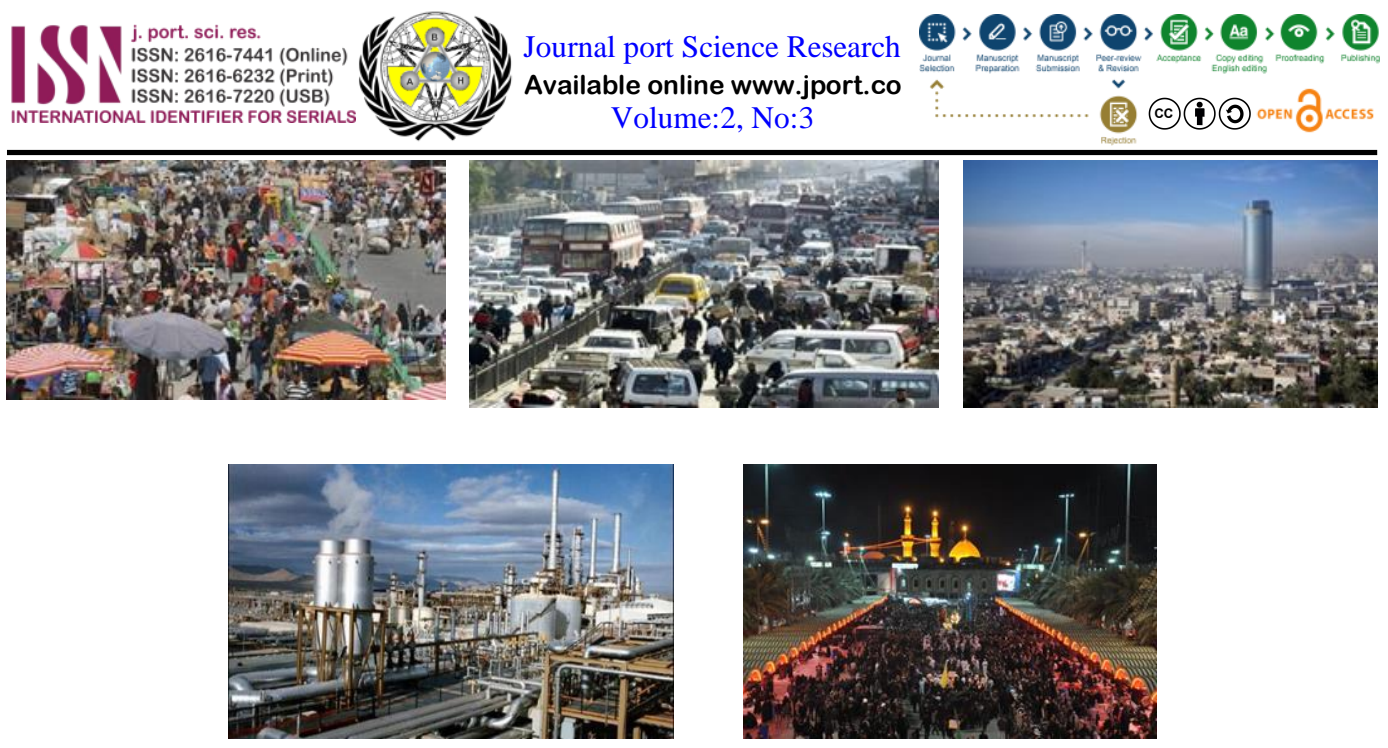

سير الدرس: (35دقيقة)

بعد عرض الصور أمام التلاهذة (طرح المفهوم المستهدف) نتعرف الان عن مفهوم المدينة وأهم ما يميزها من الأشياء, استمع الى جميع الإجابات التي طرحت من قبلهم جميعاً مع اعطاء التعزيزات الهناسبة' ثم أبدأ بشرح مفهوم المدينة وتقريبه الى أذهانهم, فالمدينة هي تجمع سكاني كبير المساحة كثير السكان, يعرف سكانه بالحضر ويعملون في مهن واعمال مختلفة كالدوائر الحكومية والشركات وفي التجارة والصناعة والخدمات الاخرى المختلفة, وسكانها في الغالب ليسوا أبنائها الاصليين فقد يكونوا قادمين أليها من قرى أو أماكن اخرى. ثم أطلب منهم ذكر المدن العراقية والمحافظة التي تقع فيها مثل (بغداد، البصرة، النجف، الحلة، كربلاء، الرمادي،

الديوانية، العمارة، الناصرية، السماوة، ديالي، أربيل، الموصل، دهوك، صلاح الدين، السليمانية، المثنى، واسط) تحديد مفهوم مألوف وذي معنى لديه نفس صفات الهفهوم الجديد وهراجعته مع التلامذة: بعد شرح وتدوين أهم مكونات المدينة وما يميزها أطلب من التلامذة أعطا مفهوم يكون قريب من مفهوم المدينة قد يشابهها في بعض الصفات وقد يختلف عنها في مواطن أخرى، في هذه المرحلة سنصل من خلال الحوار والمناقشة تمثل مناسب لبيئة الهدينة مع تقديم الدعم والتعزيز الهناسب للتلاهذة اظهروا دقة في الاجابة والتي كانت: تمثل المدينة بالأسرة الكبيرة المتكونة من الاجداد والاعمام والاخوال والوالدين والابناء والاحفاد، يسكنون اماكن متفرقة وهباني مختلفة الاحجام، ويزاولون اعمال وههن مختلفة، ويرتدون الملابس العصرية المختلفة، يتنقلون بوسائط النقل الهختلفة كالسيارات والدراجات الهوائية والقطارات.
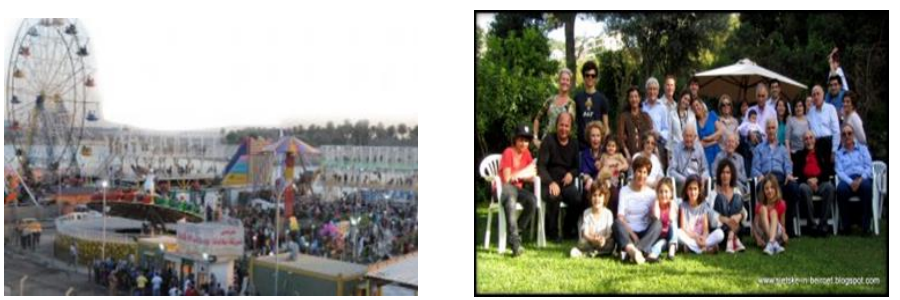

العصف الذهني للوقوف على أوجه التشابه بين المفهومين:

تعرض المعلمة على التلامذة عدد من الاسئة التي تخص النقاط المشتركة بين المفهوم الجديد(المستهدف) والمفهوم

$$
\text { القديم والتي تحفز التلاميذ على التفكير وتولد الابداع لديهم. }
$$

Al-Ta'ie, M. (2019). The Impact of The Strategy Analog Thinking in acquiring Social Content Material Concepts of Fourth Primary Class Pupils. Journal Port Science Research, 2(3), 375-396. doi.org/10.36371/port.2018.02.3.3 
التلميذ1: نعم فالأسرة الكبيرة تتكون من رجال ونساء وأطفال بأعمار مختلفة وكذلك المدينة تجمع سكاني يضم مختلف

تلميذ 2: يسكنون في مباني وبيوت مختلفة الاحجام والاشكال وهذا ما نراه ايضا في مباني المدينة المتنوعة. تلميذ 3: يرتدون الملابس العصرية المختلفة والجميلة كذلك نراه في بيئة المدينة. تلميذ 4: يعملون افراد الاسرة في اعمال ومهن متنوعة وايضاً سكان المدينة. المعلمة: جيد جدا. احسنتم أعزاءي

يشارك التلامذة في تنظيم جدول التناظر على السبورة للوقوف على أوجه التشابه والاختلاف بين العلاقتين: التناظر بين المفهومين

\begin{tabular}{|c|c|}
\hline المدينة & 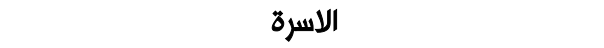 \\
\hline 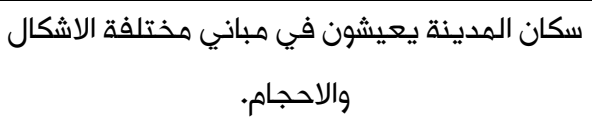 & يسكن أفراد الاسرة في غرف وهباني وبيوت مختلفة \\
\hline يرتدي سكان الحضر الملابس العصرية المختلفة. & يرتدي الملابس العصرية \\
\hline يعمل سكان المدينة في اعمال مختلفة كالشركات & يعمل أفراد الأسرة في أعمال وههن متنوعة \\
\hline
\end{tabular}

عدم التناظر بين الهفهومين

\begin{tabular}{|c|c|}
\hline المدينة & 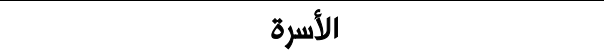 \\
\hline الازدحام السكاني والهروي للمدينة. & عدد محدود من الأفراد داخل الأسرة. \\
\hline وجود المصانع داحل المدن. & وجود الغرف المرتبة بالشكل المناسب لأفراد الأسرة. \\
\hline الضوضاء المصاحبة لكثرة السيارات والآليات. & الهدوء يعم ارجاء المنزل. \\
\hline
\end{tabular}

\section{كتابة التلاميذ لهلخص حول الهفهومين والإشارة الى عدم التناظر:}

تطلب المعلمة من التلامذة كتابة ملخص عن موضوع الدرس ليتسنى لهم فهم واستيعاب المفهوم الجديد ليصبح ذا

$$
\text { معنى ودمجه في بنيتهم المعرفية. }
$$

التقويم: لمعرفة ما تحقق من اهداف سلوكية اوجه الاسئلة التالية:

$$
\text { 1 }
$$

2) ميز الصفات والخصائص التي تنتمي والتي لا تنتهي لمفهوم المدينة.

$$
\text { 3) حدد أهم استعمالات الأرض في الهدينة. }
$$

الواجب البيتي/ اجمع صوراً لبعض المدن، وصورا اخرى تمثل الزي الذي يلبسه سكانها، واكتب تحت كل صورة اسم المنطقة والمحافظة الي تقع فيها.

الطائي، منال طه ياسين. (2019). أثر استراتيجية التفكير التناظري في اكتساب مفاهيم مادة الاجتماعيات لدى تلامدة

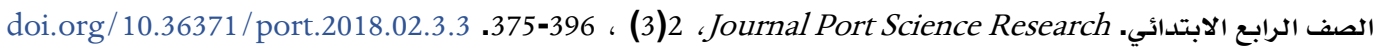

